\title{
Effects of Spatial Distance and Paid Card on Price Promotions
}

\author{
Dazhang Lei ${ }^{1,2 a}$, Naiyi $\mathrm{Ye}^{1}$ \\ ${ }^{1}$ School of Economics and Management, 610031, Southwest Jiaotong University, China \\ ${ }^{2}$ School of Economics and Management, 621010, Southwest University of Science and \\ Technology, China
}

\begin{abstract}
Paid card is an important mean of companies to maintain the customers and increase gain. It is applied extensively in retailing, fitness center, and by other service delivers. However, there is lack of studies focused on promotion mechanisms of paid card in the literature. In this paper, the promotion mechanisms of paid card based on the theories of mental accounting, construal level, and customer's perceived value. The study has the results that the intention to purchase of paid card holders is higher than that of the consumers without payment in advance in the same discount rate. When there is large spatial distance between paid card holder and the target store, the traffic mode will impact on the purchase intention of paid card holders. Finally, the study has provided the corresponding suggestions for companies' promotion management.
\end{abstract}

Keywords. paid card; spatial distance; price promotions

Reducing customer's attrition has important impacts on a company's profit, so many companies start to employ paid card to maintain the customers. The nature of a paid card is that customers pre-purchase a class of products or services. However, what a specific product or service and when will be bought is not yet determined. That is a latent price bundling and is characteristic that payment and consumption are separate. There is lack of studies about the influences that the paid card leads to separate transactions on consumption behaviors in the literature. This paper applies the theories of mental accounting, construal level, and customer's perceived value to study the promotion mechanisms of paid card. We firstly review the literature related to the transaction separation caused by paid card, and develop the conceptual framework and hypothesis. Then, we collect data through survey and scenarios experiments, and analyze the data and test the hypothesis.

\section{Theoretical Basis and Research Framework}

\subsection{Transaction Decoupling, construal level, and value judgment}

\footnotetext{
${ }^{a}$ Corresponding author: lei200711@yeah.net
} 
The length of time between payment for the transaction and product obtaining will impacts on consumer's value judgment and consumption behavior. Prelec \& Loewenstein (1998) note, for the product purchase with payment in advance and delayed consumption, consumer's obtained hedonic value from delayed consumption is higher than that from payment and consumption timely coupling transaction. For the consumer may view the payment in advance as activity of a sort fund raising and the delayed consumption as a free activity. Gourville \& Soman (1998) demonstrate that the influence of payment in advance will be decreased with the passage of time when there is a relatively large time span between the payment in the transaction and obtaining the benefits from the consumption. When products may not be stored, consumers will reduce their consumptions; when products may be stored, consumers will increase their consumptions.

Price promotions, especially the price bundling strategies, may create decoupling cost of purchase and benefits of consumption (Prelec \& Loewenstein, 1998; Soman \& Gourville, 2001). Soman \& Gourville (2001) reveal in their investigations that the effects of sunk cost will be influenced by the decoupling the cost of product purchase and the benefits of product consumption. When the both are decoupled closely, the effects of sunk cost will increase the possibility of consumers' consumptions. However, when the cost of product purchase and the benefits of product consumption are decoupled, the possibility of consumers' consumption could be reduced, the requirement of compensation if there is no consumption and regret caused from product will be reduced. For consumers will face on cognitive difficulties about how much the cost should be shared to the delayed consumptions with the increasing consumptions and lapse of time. Price bundling strategy will increase the possibility of decoupling transaction cost and product benefits for consumers.

Time span and spatial distance impact on purchasers' criteria of choice value judgment through psycho distance. The construal level theory demonstrates that purchaser will mainly consider the possibility of alternative set toward the event of near psycho distance; and purchaser will mainly consider longings of alternative set toward the event of far psycho distance (Malkoc et al., 2005; Liberman et al., 2007; Leiser et al., 2008).

\subsection{Judgment of customers' total cost and value}

Customer's perceived value is determined through comparing the customer's total value to the total cost. When the expenditures of a product or service are separated from the consumption timely, payment will be complete one time, but the product or service will be obtained in severe transactions. Therefore, when customers assess the value of continuous consumptions, the customer's total value is deterministic, but it is uncertain to the cost of time, effort, labor and a little money that customers need to pay for consuming them. How consumers evaluate various costs such as time, effort, labor and money will be the major basis of judging the value for consumptions.

Among customer's total cost, time and labor costs may be perceived. In other hand, the costs of money, psycho cost and their impacts on the customers may not be easily perceived. Based on the construal level theory, consumers will change the evaluation criteria for purchase choices when the time and spatial distances vary: when the distance is far, they tend to apply the abstract evaluation criteria; when the distance is closed, they tend to apply the concrete criteria. When sunk cost and time cost are given, the money and labor costs etc. for consumption are correlated with spatial distance closely. When the spatial distance is more closed, the expenditure of money and labor will be lower; when the spatial distance is farther, the expenditure of money and labor will be higher.

Purchaser with payment in advance may enjoy price discount. So, whether to have paid card becomes the issue of purchasing at discount price or at whole price. For the customer who holds paid card, potential loss (sunk cost $)=$ prepaid amount of money + through price discount reduced expenditure - expenditure for purchasing; for the customer without paid card, potential loss (sunk cost $)=$ amount of money calculated from the whole price - amount of money calculated from the 
discounted price. From perspective of long term, prepaid amount of money may reduce relatively large amount of money for future consumptions. For each time purchasing, the saved amount of money is very few and almost not perceived because the quantity of product or service is low. The major criteria of judging superior or inferior purchase will be based on the acceptance of spatial distance and time consumption. Therefore, at the same price discount rate, the purchaser's perceived value for the transactions without payment in advance is lower than that with payment in advance, and the purchase intention of the purchaser with payment in advance will be higher than the purchaser without payment in advance because of the impact of loss aversion. So, we have the following hypothesis:

H1: For paid card holders, the non-monetary costs to the purchase process is lower, the purchase intention of paid card holders will be higher

$\mathrm{H} 2 \mathrm{a}$ : The higher discount rate is; the higher purchasing intention the paid card holder has.

$\mathrm{H} 2 \mathrm{~b}$ : When the price discount rate is same, the purchase intention of paid card holders is higher than that of consumers without payment in advance.

The research framework is illustrated as the Figure 1:

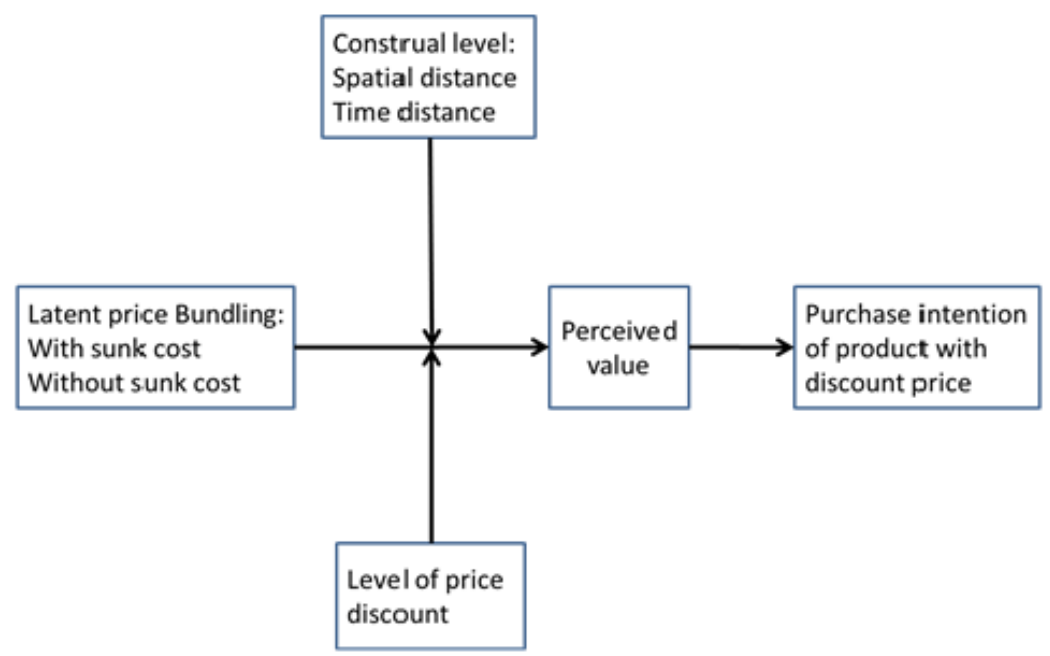

Figure 1. Effects of price promotion of sunk cost, spatial distance, and latent price bundling

\section{Research design}

\subsection{Experiment design}

We choose paid card as stimulus, and apply scenarios experiment design: the experiment requires the respondents first read the information according to the scenario, and then answer the related questions.

We determine the discount level through two ways. Firstly, we conduct focus group and individual interview to paid card holders and potential consumers to get the information about the discount level of paid card. Secondly, we interview a number of business persons from retailing industry about how the paid card is used and its discount level. We get the result from focus group and interviews that the discount range of the most paid cards is between $50 \%$ and $20 \%$. So, we designed two discount levels of $40 \%$ and $20 \%$ in the experiment.

The experiment has two scenarios: before holding paid card and after holding paid card. The scenario before holding paid card is designed as the following: 
You have just purchased 100 Yuan RMB products in a specialty store and ready to pay, the cashier says: If you have deposited 500 Yuan RMB to apply for a membership paid card, then you may enjoy the preferential term of $20 \%$ or $40 \%$ price discount. The purchased product today will be also paid with discount price according to the preferential term. The products you have purchased may be paid at discount price, and the money will be disbursed from the paid cared. The money deposited in the membership paid card can be disbursed without time limits. If you have no paid card, your purchased product has to be charged at the tag price.

The scenario after holding paid card is designed as the following:

You are ready to buy some articles for daily use and the estimated expenditure would be 50 Yuan RMB. A store you hold its paid card offers the articles you need for today. The balance of your paid card remains 400 Yuan RMB. If you are going to buy the articles in this store by using the paid card, you will enjoy the preferential terms of $40 \%$ or $20 \%$ price discounts.

You have to spend at least 20 minutes to drive to the store, and at least 35 minutes to the store by bus( Driving to the store needs 20 minutes but it is difficult to park near the store; Riding a bus to the store needs 35 minutes/walking to the store needs at least 20 minutes).

\subsection{Measurement of variables}

\subsubsection{Purchase intention}

The dependent variable of this study is consumer's purchase intention. It covers the items of (1) weather you are going to apply for the paid card; (2) weather you are going to purchase or consume in the store you hold its paid card; and (3) weather you are going to pay for your purchasing by using your paid card.

\subsubsection{Measurement of perceived transaction value}

By measuring the perceived value in this study, we mainly referred the measures in the studies of Grewal, Monroe \& Krishnan (1998), Sweeney \& Soutar (2001), and Liaogang Hao, Congyan Gao\& Jianmin Jia (2008) in the literature. Based on the referring, we designed 3 items: (1) I feel it is worthwhile to pay by membership paid card; (2) I feel it is good value for money to pay by membership paid card; (3) I feel it is attractive to pay by membership paid card.

The purchase intention and perceived value are measured by Likert 7 scales.

\subsection{Sampling and data collection}

After the experimental scenarios and questioners are completed, we authorize Questionnaire Star to provide sampling and data collection services. We require that the respondent has to hold paid card, each respondent's IP address may only answer one questionnaire from 6 group questionnaires. We have 6 groups of questionnaires. Each group questionnaires requires 50 respondents. All together we need 300 respondents.

We have collected the data with the help of Questionnaire Star through Internet. After getting rid of obviously invalid questionnaires and to that the answer time was abnormal, we have obtained 196valid questionnaires. Among the respondents, there are 79 males, 117 females. Over $90 \%$ of them have college and above education. The respondents hold at least 2 paid cards, such as purchasing paid card, fitness paid card, and car wash paid card, and so on.

\section{Data Analysis}

\subsection{Impacts of price discount rate and traffic modes on purchase decisions}


We conducted two factors ANOVA analysis by taking price discount rate and transport pattern as independent variables, and perceived transaction value as well as purchase intention as dependent variable. Firstly, the homogeneity has been tested: $F(3,114)=2.355, p=0.076>0.05$. So, to conduct ANOVA analysis is accepted. The results of the ANOVA analysis reveal that the cross effect of price discount rate and transport mode on purchase intention is not significant: $F(1,117)=$ $0.999, p=0.32>0.05$. The effect of the price discount rate on purchase intention is not significant: Mean $_{40 \% \text { discount }}=4.952$, Mean $_{20 \% \text { discount }}=4.880, \mathrm{~F}(1,117)=0.086, \mathrm{p}=0.769>0.05$. The effect of transport mode on purchase intention of paid card holders is significant: Mean walk $=4.637$, Mean drive $=5.195, \mathrm{~F}(1,117)=5.116, \mathrm{p}=0.026<0.05$. The hypothesis $\mathrm{H} 1$ has been tested. The Impacts of price discount rate and traffic modes on purchase decisions of paid card is illustrated as the figure 2:

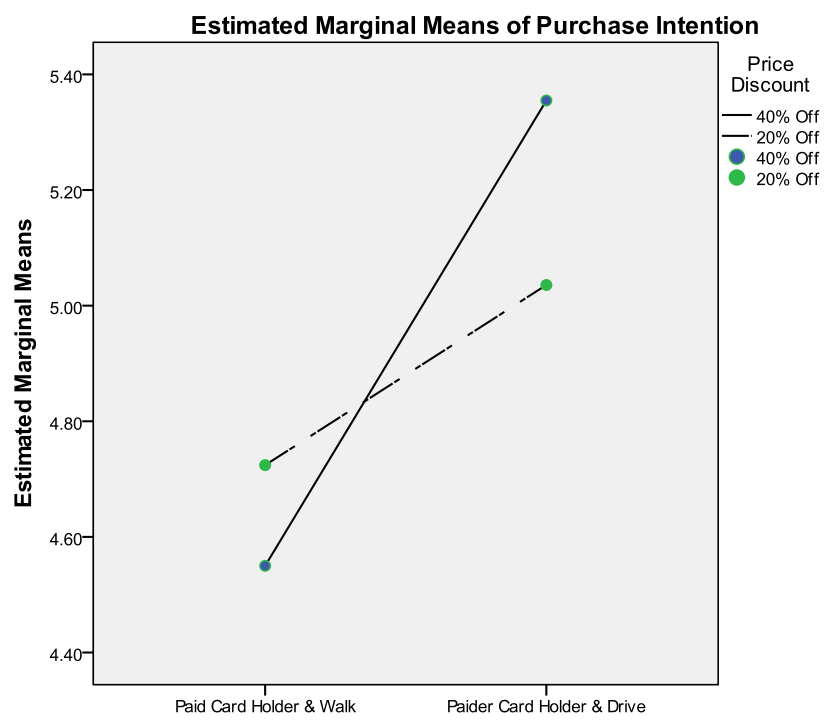

Figure 2. Impacts of spatial distance and traffic modes on purchase decisions

\subsection{Impacts of spatial distance, paid card holding on purchase intention}

The effects of spatial distance and paid card holding on purchase intention have been investigated in this experiment. We take paid card holding (not holding) and price discount rate $(20 \%$ and $40 \%)$ as independent variables, and purchase intention as dependent variable. Firstly, we have tested the homogeneity and have the results: $\mathrm{F}(3,133)=0.936, \mathrm{p}=0.425>0.05$. So, to conduct ANOVA analysis is accepted. The comparison of effects between groups reveal that cross effect between price discount rate and paid card holding is not significant: $F(1,136)=0.036, p=0.549>0.05$. In the analysis, 4 groups of the respondents have the following mean value of purchase intention: Mean $_{\text {paid card holder } \times 40 \% \text { Off }}=5.355$; Mean paid card holder $\times 20 \%$ Off $=5.036$; Mean not paid card holder $\times 40 \%$ Off $=$

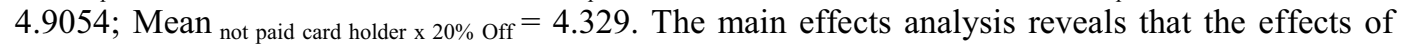
paid card holding and price discount rate are all significant. Paid card holding: $F(1,136)=7.286$, $\mathrm{p}=0.008<0.05 ;$ Price discount rate: $\mathrm{F}(1,136)=4.371, \mathrm{p}=0.038<0.05$. 


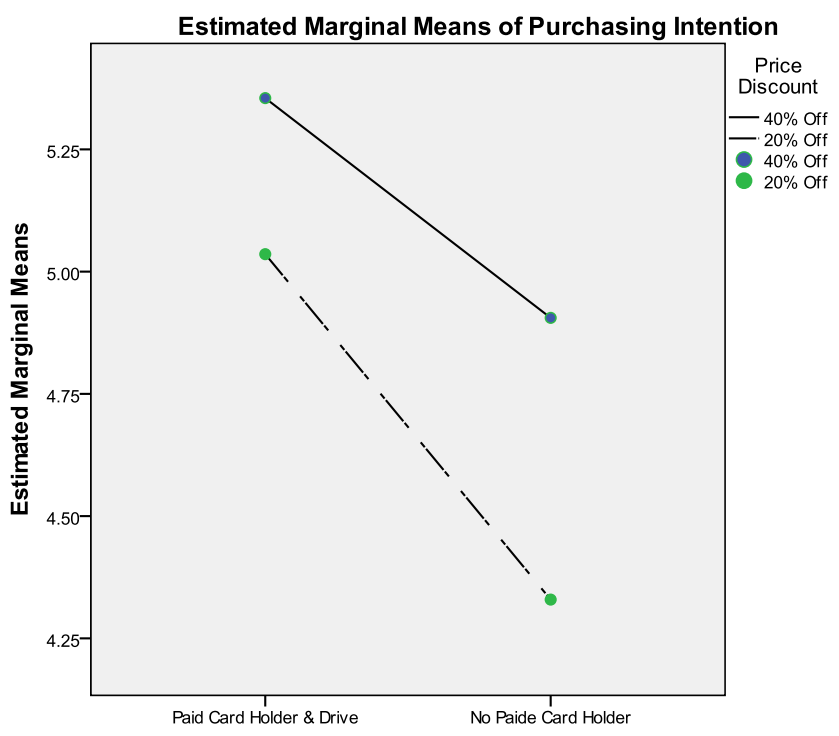

Figure 3. Impacts of spatial distance, paid card holding on purchase intention

The results demonstrate that the consumers' purchase intention is influenced not only by price discount rate but also by payment in advance: the higher the price discount rate is, the higher the purchase intention is; and the purchase intention of paid card holder is higher than that of not paid card holder. For the paid card holders, the price discount was purchased through payment in advance of a specific amount, and the amount of payment in advance is sunk cost. If they do not go to shopping in that store, they will suffer the loss. Meanwhile, when there is large distance between the consumer and the store issuing paid card, consumers usually apply some abstract constructs to assess the value of purchased products, such as the satisfaction to the purchased products etc., therefore, their purchase intention generally is higher. For the consumers who do not hold paid card, to apply for a paid card requires to pay a large amount of money in advance. In other hand, if they do not apply for the paid card, they are going to pay the products without price discount. The amount of the price discount is relatively small. So, to evaluate the attributes of product becomes the major impact factor on consumers' purchase intention. Therefore, consumers' intention is relatively low that first applying for paid card and then purchasing products.

\section{Conclusion and managerial implications}

This study has two major findings: Firstly, for the consumers with decoupled between payment and consumption, the paid card will generates sunk cost which may remain its customers and stabilize the sales of the store; Secondly, when paid card holders are separated from the target store in space, the spatial distance will cause the change of assessment criteria to the behavior of paid card holders, thus that will affect the purchase decision.

Those findings have important managerial implications for enterprises. Firstly, for the retailing stores that locate in not prosperous section in cities, they should not only conduct marketing promotions, but also solve service problems, such as to increase stations of mass transit, provide free shopping buses, as well as free parking. Secondly, they may integrate the price discount and latent price bundling, and encourage consumers to enjoy the benefits of price policies through payment in advance. Thirdly, they may change the business model of only waiting consumers coming in the store to shop, and add the services that delivery their products to home of consumers. Currently, the traffic jam and difficult parking become the major factors influencing on the 
consumers' choice of retailing places. The retailers may consider the business model of placing orders online and delivery the products at home, in order to stimulate the consumptions of buyers.

\section{References}

1. D. Prelec, G. Loewenstein, MS, 1998: 4-28.

2. J.T.Gourville, D. Soman, JCR, 1998: 160-174.

3. D.Soman, J.T.Gourville (2001), JMR, 2001: 30-44.

4. S. A. Malkoc, G. Zauberman, C. Ulu, PS, 2005: 411-417.

5. Liberman N., Y. Trope, C. Wakslak, J C P, 2007: 113-117.

6. D. Leiser, O.H. Azar, L. Hadar, JEP, 2008: 762-776.

7. D.Grewal, K.B.Monroe, R. Krishnan, JM, 1998: 46-59.

8. J.C.Sweeneya, G.N. Soutar, JR, 2001: 203-220.

9. L.Hao, C.Gao \& J. Jia (2008), MW, 2008: 106-117. 